\title{
A DIVERSIDADE NO USO E OCUPAÇÃO DA ZONA COSTEIRA DO BRASIL: A SUSTENTABILIDADE COMO NECESSIDADE
}

\author{
Fabiana Lima Abreu ${ }^{1}$, Fábio Perdigão Vasconcelos ${ }^{2}$, Mária Flávia Coelho Albuquerque $^{3}$ \\ ${ }^{1}$ Instituto Federal de Educação, Ciência e Tecnologia do Ceará - IFCE, campus de Fortaleza \\ ${ }^{2}$ Universidade Estadual do Ceará - UECE \\ ${ }^{3}$ Secretaria de Educação do Estado do Ceará \\ <fabiana@ifce.edu.br>,<fabioperdigao@gmail.com>. \\ $<$ flavia072013@gmail.com>
}

DOI: $10.21439 /$ conexoes.v11i5.1277

\begin{abstract}
Resumo. A ocupação não sustentável ao longo das costas brasileiras, tem intensificado e acelerado processos de erosão das praias, de poluição de mares, lagoas, estuários e de descaracterização da cultura local. Esse trabalho trata-se de uma compilação bibliográfica e tem como objetivo explicitar as principais formas de uso e ocupação do litoral, incluindo a atividade turística, ressaltando a complexidade do ambiente costeiro e a relevância de atitudes e tomadas de decisões sustentáveis. Por fim, traz reflexões importantes sobre a necessidade de uma análise integrada da zona costeira, ou seja, uma abordagem que inclua preocupações ambientais, econômicas, sociais e culturais, promovendo uma distribuição mais justa das oportunidades, quer seja entre a população atual, quer seja entre as gerações atuais e futuras.
\end{abstract}

Palavras-chaves: Zona Costeira. Uso e ocupação. Gestão integrada. Sustentabilidade.

Abstract. The unsustainable occupation along Brazilian coasts has intensified and accelerated processes of beach erosion, pollution of seas, lagoons, estuaries and de-characterization of the local culture. This work is a bibliographical compilation and aims to explain the main forms of use and occupation of the coast, including the tourist activity, highlighting the complexity of the coastal environment and the relevance of attitudes and sustainable decision making. Finally, it provides important insights on the need for an integrated analysis of the coastal zone, ie an approach that includes environmental, economic, social and cultural concerns, promoting a fairer distribution of opportunities, whether between present and future generations.

Keywords: Coastal Zone. Use and occupation. Integrated management. Sustainability.

\section{INTRODUÇÃO}

Devido a fatores históricos relacionados à ocupação do território brasileiro e seguindo a tendência mundial da população em ocupar predominantemente áreas próximas ao litoral, o Brasil apresenta $26,6 \%$ da população vivendo em municípios da zona costeira. Parte dessa população está ocupada em atividades ligadas ao turismo de forma direta ou indireta, como a produção de petróleo e gás natural, a pesca e os serviços que atendem à dinâmica econômica gerada por esses municípios e outros próximos(IBGE, 2011) . Essa elevada e sempre crescente população tem sido responsável pela grande pressão sobre os ecossistemas costeiros e prin- cipalmente sobre aqueles localizados em regiões próximas aos grandes centros urbanos. Por causa deste contingente demográfico, inúmeras baías, estuários, lagoas e mares estão poluídos, resultando em sérios danos ambientais, econômicos, sociais e culturais, pois o comprometimento do ambiente costeiro causa prejuízos para a fauna e flora diminuindo, entre outras atividades, a pesca e o lucro provindo dela. A pesca diminuída, o pescador busca outras atividades para o sustento da família, abandonando seus costumes, perdendo a sua identidade. Uma vez que as características físicas e culturais do local são modificadas, o que havia de beleza propícia à atividade turística também se perde. O ambiente e a cultura sofrem alterações diversas e assim não 
há mais encanto que encante nenhum novo olhar sobre aquele lugar. Dessa forma, busca-se outros lugares que ainda possuem as suas belezas naturais e esquece-se a população e a natureza do lugar anterior. A intervenção humana não sustentável, através da ocupação de dunas, de faixa de praia, de planície flúvio-marinha, além dos desmatamentos, de barragens nos rios etc., tem intensificado e acelerado o processo erosivo, contribuindo para o aumento da erosão costeira. Outro rastro da intervenção do homem na zona costeira é ocasionado pelos esgotos domésticos que atingem diretamente a vida marinha e aos que vivem no litoral.

[..]O esgoto (industrial e doméstico) constitui uma das grandes ameaças para a vida marinha e para quem vive no litoral porque age como um fertilizante. O esgoto leva para o mar grande quantidade de matéria orgânica (nutrientes), que acaba contribuindo para a explosão do ficoplâncton. A vida microscópica cresce de forma desordenada, prejudicando outros organismos marinhos que ficam sem espaço, sem oxigênio e sem nutrientes. A poluição pode atingir drástica e rapidamente o ambiente marinho, com morte instantânea do plancton, ou ainda pela bioacumulação, que é o fenômeno através do qual os organismos vivos acabam retendo dentro de si algumas substâncias tóxicas que vão se acumulando também nos demais seres da cadeia alimentar até chegar ao homem, sendo um processo lento de intoxicação e muitas vezes letal. (IBAMA 2002 p. 119)

De acordo com o IBAMA (2002, p. 122), os dados da Associação Brasileira de Entidades do Meio Ambiente (ABEMA) mostram que, cerca de $80 \%$ dos esgotos do Brasil não recebem nenhum tipo de tratamento antes de serem despejados nos rios, lagoas, mananciais e mares. Este procedimento ocasiona a poluição e contaminação dos recursos hídricos, inclusive dos lençóis freáticos. Sendo assim, é necessário atentar para a qualidade da água dos poços profundos que podem estar contaminadas pelos dejetos lançados nos mananciais ou mesmo no solo, afetando diretamente a saúde da população consumidora. A perspectiva de aumento populacional na zona costeira levanta reflexões a respeito das políticas públicas destinadas a essas áreas. A falta de gestão, de estratégias de manejo que levem em conta à redução de impactos sócio-ambientais mostrando a necessidade, cada dia maior da gestão integrada das regiões litorâneas, na perspectiva da sustentabilidade. De outra parte, além dos esgotos domésticos há também os industriais. Cinco dos nove maiores centros urbanos do Brasil localizam-se na zona costeira: Fortaleza, Rio de Janeiro, Salvador, Recife e Belém, sendo este último em região estuarina. Em todas essas cidades há portos na zona costeira que atraem diversas indústrias em seu entorno, muitas das quais lançam seus esgotos nos estuários, rios e mares, poluindo e contaminando a fauna local, causando prejuízos irreparáveis para o meio ambiente. Um outro uso da zona costeira está relacionado à atividade da carcinicultura que oferece o risco de não ser sustentável devido ao grande impacto que gera desde a implementação até a execução de projetos do setor. A crescente utilização dos rios e mangues, para a atividade de aqüicultura tem sido feita, em muitos casos, de forma degradadora, sem a devida preocupação de não poluir esse ecossistema.

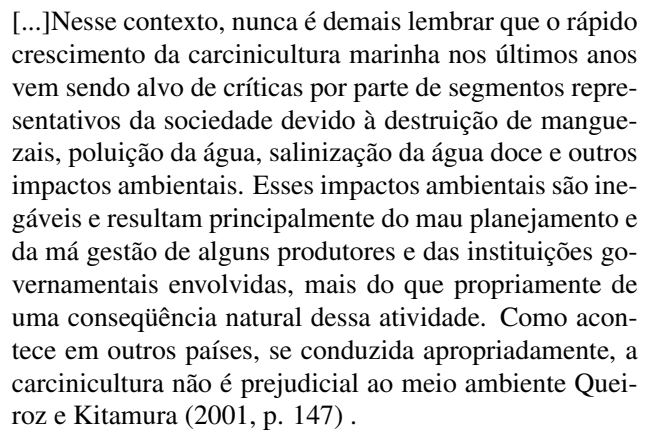

Uma outra fonte poluidora das águas dos rios e também dos estuários são as atividades agrícolas que utilizam agrotóxicos sem a devida orientação quanto à quantidade a ser aplicada, a forma como deve ser feito o manuseio e o destino final dos recipientes vazios. A pesca, a atividade de maior destaque nas pequenas comunidades litorâneas também passou a sofrer os efeitos das novas ocupações da zona costeira, uma vez que a pesca artesanal cedeu lugar à indústria pesqueira moderna no final da década de 1960. A pesca artesanal sobrevive sendo fonte de renda e emprego. "Essas empresas pesqueiras capturam alguns produtos nobres como o camarão, a lagosta e algumas espécies de peixes". Como elas possuíam um grande incentivo fiscal necessitavam de retorno rápido o que gerou a devastação dos recursos pesqueiros em algumas regiões do País.(DIEGUES, 2004, p. 131). Essas empresas modernas, com seus grandes barcos, a partir daí passaram a entrar em conflito com os pescadores artesanais e seu sistema de manejo tradicional e da grande devastação dos recursos pesqueiros. O resultado foi que alguns pescadores abandonaram a profissão.

[...]É relevante destacar o lado de conflito e de compe-
tição entre a pesca artesanal e industrial. Nesses casos,
historicamente, o Estado posiciona-se, face ao conflito,
de maneira claramente favorável aos empresários capita-
listas, seja se omitindo de uma clara luta entre dois seg-
mentos diferentes e antagônicos, seja colocando as prio-
ridades econômicas acima dos conflitos de classe, refor-
çando a dominação dos empresários sobre os pequenos
produtores. O Estado, através de estratégias induzidas, 
provocou um aumento de capitais, ao investir maciçamente nas grandes empresas. Ignorou, ainda, a riqueza e complexidade de formas organizativas endógenas da pequena produção. Tomou como requisito dual - antigo versus moderno - como esferas independentes de atividades e considerou o pequeno pescador como indivíduo reacionário, inculto e predador, incapaz de assimilar os padrões tecnológicos aspirados pelo Estado e a burguesia industrial (LOUREIRO 1985.

Aliada à pesca industrial, nas zonas costeiras do Brasil deu-se também a crescente expansão da atividade turística (turismo de massa) $\sqrt{1}$ e de especulação imobiliária. Principalmente a partir da década de 1970, o número de turistas que se destinam às regiões litorâneas tem aumentado e a instalação de complexos hoteleiros, pousadas e demais infra-estruturas voltadas para essa atividade tem ocasionado problemas não só ambientais como também sociais. Sobre este ponto, (DIEGUES 2004, p. 131) comenta que "os pequenos produtores costeiros foram alijados de seus territórios tradicionais, expulsos de suas praias para dar lugar a complexos turísticos hoteleiros". Uma outra atividade de relevância quando se fala dos diferentes usos do litoral e os diferentes impactos que podem ser gerados, é o turismo, que quando não vem acompanhado de um planejamento que permeia as escalas, territorial, social, econômica, administrativa e cultural, pode gerar a descaracterização desse lugar, dentre outras questões pela chegada de grandes condomínios e/ ou grandes empreendimentos turísticos, que por sua vez irão gerar uma série de conflitos territoriais, que podem ser vislumbradas desde a limitação do acesso a praia até as questões relacionadas ao declínio de atividades tradicionais como a pesca e a expropriação do território propriamente dita.

\section{[...]Além do fato de essa expansão vir ocorrendo de forma desordenada e às expensas da incorporação de áreas de grande relevância ambiental (dunas, mangues, etc.), ela também transfere para espaços novos, parte dos vetores de comprometimento ambiental típicos das gran- des aglomerações, tais como: contaminação das águas subterrâneas, superficiais e das praias, remoção da co- bertura vegetal e de solos, interferência na dinâmica de carreação de sedimentos marinhos. Dentre todos os ve- tores de ocupação esse é o que mais ameaça, atualmente, a integridade dos ecossistemas ainda bem preservados. (IBAMA 2002 p. 125)}

Com o turismo de massa, é importante salientar, muitos pescadores foram sendo "expulsos" do seu território e acabaram abandonando a profissão por ter-se tornado inviável, dada a distância de sua moradia, do

\footnotetext{
${ }^{1}$ Visa o uso intenso da localidade sem a preocupação com o sustentável, fazendo com que aconteça a saturação dos bens naturais, sociais e culturais.
}

mar. Em outras palavras, essa nova forma de ocupação do litoral, ou mesmo essa nova territorialidade 2 , em ascensão na zona costeira, gerou desterritorialização daqueles que nasceram e construíram suas vidas ali. Essa desterritorialização faz as pessoas se desenraizarem e procurarem novos territórios para reconstruir suas vidas. Vinculado a esse crescente aumento do turismo de massa, surge a ideia de um turismo mais preocupado com o meio físico e com a cultura dos lugares. Em meados dos anos 1990 aparecem as primeiras experiências no Brasil de Turismo de Base Comunitária (TBC), segundo o Ministério do Turismo brasileiro. Esse tipo de turismo, diferente do turismo de massa, apresenta preocupação com os impactos ambientais, a gestão é coletiva e liderada pela comunidade e considera a cultura local o principal atrativo turístico.

\section{[...]De maneira geral, o turismo comunitário pode ser en- tendido como uma atividade turística que apresenta ges- tão coletiva liderada pela comunidade, transparência no uso e destinação dos recursos e na qual a principal atra- ção turística é o modo de vida da população local. Nesse tipo de turismo, geralmente, a comunidade é proprietá- ria dos empreendimentos turísticos e há a preocupação em minimizar o impacto ambiental e fortalecer ações de conservação da natureza. (GABRIELLI; SANTOS 2016)}

No Ceará, o turismo comunitário ganha visibilidade a partir da Rede Tucum. Essa Rede abrange diversas comunidades no Estado e mostra ao mercado nacional e também internacional um produto turístico voltado para a proteção e valorização das culturas e dos territórios economicamente integrados às atividades tradicionais. Segundo Gabrielli e Santos (2016) :

[...]a Rede Tucum conta com a participação de dez comunidades costeiras, entre indígenas, pescadores e moradores de assentamentos rurais, dois pontos de hospedagem solidária em Fortaleza, além de duas ONGs que fazem o apoio institucional à rede - Instituto Terramar (Brasil) e Associação Tremembé (Itália).

${ }^{2}$ Territorialidade "refere-se ao conjunto de práticas e suas expressões materiais e simbólicas capazes de garantirem a apropriação e a permanência em um dado território por um determinado agente social, o Estado, os diferentes grupos sociais e as empresas". (CORREAA 2002 p. 251). Diz (CORRÊA 2002 p. 252) que essa "desterritorialização é entendida como a perda do território apropriado e vivido, em razão de diferentes processos derivados de contradições capazes de desfazerem o território". "Etimologicamente território significa terra pertencente a alguém, no entanto, não está necessariamente vinculado à propriedade da terra, mas à sua apropriação. Estando esta apropriação, por um lado, associada ao controle efetivo por parte de instituições ou grupos sobre um dado segmento do espaço (...). Por outro lado, pode o conceito de território assumir uma dimensão afetiva por parte de grupos definidos segundo a renda, a raça, a religião, o sexo, a idade ou outros atributos. Aqui este conceito está associado a uma Geografia que privilegia os sentimentos e simbolismos atribuídos aos lugares. A apropriação passa a associar-se à identidade de grupos e à afetividade espacial.(CORRÊA 2002 p. 251) 
O olhar para produtos e ações sustentáveis cresce no Brasil e no mundo. A preocupação em garantir, para as novas gerações, um planeta viável para se viver, faz com que diversos países se comprometam a interligar as suas economias a uma forma de lucro mais sustentável.Agora no ano de 2017, a Organização das Nações Unidas proclamou o ano Internacional do Turismo Sustentável para o Desenvolvimento ${ }^{3}$ reconhecendo a importância da atividade turística no mundo todo, uma vez que ela responde por cerca de $10 \%$ da atividade econômica mundial. E também para contribuir com a luta contra a pobreza e promover o diálogo intercultural.

\begin{abstract}
[...]O Ano Internacional do Turismo Sustentável para o Desenvolvimento é uma oportunidade para fortalecer a dinâmica positiva entre o patrimônio e o turismo (...). O turismo sustentável requer novas parcerias para melhor educar e informar, de modo a estimular novos comportamentos e fortalecer o comprometimento entre todos os envolvidos com o turismo (...), para garantir que o turismo sustentável seja um catalisador de mudanças positivas do comportamento mundial. (UNESCO 2017)
\end{abstract}

A UNESCO (2017) desenvolve um programa chamado World Heritage Programme (Programa do Patrimônio Mundial) que vem desenvolvendo ações com o intuito de garantir que os turistas que visitam seus 1.052 sítios naturais e culturais beneficiem as comunidades locais e que os fluxos de visitantes sejam administrados de maneira compatível com a conservação do patrimônio.

\section{FUNDAMENTAÇÃO}

Nas últimas décadas, com a tomada de consciência dos problemas decorrentes da degradação ambiental, não só do litoral, mas de todos ambientes, acima de sua capacidade de suporte, surgem então os conceitos de gestão integrada e de sustentabilidade. A natureza, tratada como mercadoria ou estoque infindável de recursos, sofreu danos irreparáveis, diante da busca desenfreada produzida pela ideologia capitalista por mais status social, fundamentado na quantificação de bens materiais adquiridos.

Desta maneira pode-se dizer que, atualmente, o ritmo de consumo levantou uma crise sem precedentes na história do homem, constituindo um cenário de escassez de recursos e degradação ambiental irreversível. As consequências deste estilo de desenvolvimento sobre o meio ambiente são inúmeras. Chuvas ácidas, inundações, redução do potencial hídrico do planeta, poluição dos rios e ar, redução da camada de ozônio que

\footnotetext{
${ }^{3}$ Disponível em:< http://www.bdt.fat.org.br/publicacoes/politica /agenda21/cap8> Acesso em: 13/07/2011
}

protege o planeta da radiação, aquecimento do clima, degelo, aparecimento de inúmeras doenças ocasionadas pela poluição, são alguns dos graves exemplos das consequências e do nível de degradação da natureza em que o planeta se encontra. E, como consequências socioeconômicas, temos o aumento da desigualdade social, a diminuição do número de postos de trabalho, a perda do poder de compra de alguns segmentos da classe média, entre outros. A educação, tornou-se, para a sociedade, um comércio lucrativo e o acesso à saúde cada vez mais diferenciado. Entendeu-se que o modelo precisou ser mudado.

Nesse sentido torna-se urgente o debate pela luta por um desenvolvimento que esteja preocupado com o meio ambiente saudável, com justiça social e cidadania. Assim, ganha lugar a questão ambiental que até 1960 era pouco comentada e a partir de então passou a ser considerada como um problema global. Os danos e desastres ecológicos levantaram questões sobre a defesa ambiental. Esse pensamento tomou proporções planetárias quando, em 1971, o Clube de Roma, entidade que reunia cientistas de vários países, publicou o livro "Limites de Crescimento", contendo os resultados dos estudos liderados pelo cientista Dennis Meadows que apontava que a humanidade no século XXI iria se defrontar com graves problemas, se não mudassem os padrões de produção e consumo. Em junho de 1972, em Estocolmo, a ONU promoveu a Conferência das Nações Unidas sobre o Meio Ambiente Humano e discutiram os principais problemas ambientais do Planeta e suas relações com a ameaça de sobrevivência da vida humana.

Em 1983, constitui-se a Comissão Mundial sobre o Meio Ambiente e o Desenvolvimento (CMMAD) para estudar as questões relacionadas com o desenvolvimento da humanidade. Os resultados dos estudos desta comissão foram reunidos no Relatório "Nosso Futuro Comum" em que constava, pela primeira vez, o termo "desenvolvimento sustentável", na tentativa de incorporar o conceito de sustentabilidade ao conceito de desenvolvimento. Desse modo, desenvolvimento sustentável foi conceituado como "um processo de transformação no qual a exploração dos recursos, a direção dos investimentos, a orientação do desenvolvimento tecnológico e a mudança institucional se harmonizam e reforçam o potencial presente e futuro, a fim de atender às necessidades e aspirações humanas"(CMMAD. 1988 apud BARBIERI, 1988, p.25). Apesar de aparentemente simples, este conceito carrega em si todas as dificuldades inerentes ao confronto da perspectiva capitalista, centrada no mercado e no lucro, com a perspectiva da solidariedade e da responsabilidade para com as 
gerações futuras. Nesse sentido, consiste um dos grandes desafios para implementar este conceito a definição de quais são as necessidades da atual geração e quais serão as necessidades das gerações futuras.

No Brasil, a preocupação com o meio ambiente veio à tona já na década de 1980 quando foi instituída a Lei n. ${ }^{\circ} 6.938$, de 31 de agosto de 1981 que dispõe sobre a Política Nacional de Meio Ambiente (PNMA) cujo objetivo era implementar, no país, "a compatibilização do desenvolvimento econômico-social com a preservação da qualidade do meio ambiente e do equilíbrio ecológico", pensando o meio ambiente como um patrimônio público e "tendo em vista o uso coletivo" (MORAES. 1999, p. 146) . No entanto, a preocupação com a zona costeira do país e seu estado de ocupação e degradação só veio se firmar mais tarde, em 1988 através da Constituição Federal, que, no parágrafo 4 do artigo 225, define a Zona Costeira como "patrimônio nacional" e especifica que sua utilização deve ser feita "na forma da lei, dentro de condições que assegurem a preservação do meio ambiente, inclusive quanto ao uso dos recursos naturais". (MORAES, 1999 p. 142).

A ideia de uma análise do litoral de forma integrada surgiu no Brasil com a PNGC/GERCO e depois com a Agenda 21. O Plano Nacional de Gerenciamento Costeiro (PNGC) foi instituído no dia 16 de maio de 1988 através da Lei n. ${ }^{0} 7.661$ e regulamentado pelo Decreto Federal 5.300 de 7 de dezembro de 2004. O objetivo principal desse programa é "o estabelecimento de normas gerais visando à gestão ambiental da Zona Costeira do País, lançando as bases para a formulação de políticas, planos e programas estaduais e municipais". (MMA, 2004).

Esse programa visa, ainda, a promoção e o ordenamento dos recursos naturais e da ocupação dos espaços costeiros; o estabelecimento do processo de gestão das atividades socioeconômicas na Zona Costeira de forma integrada, descentralizada e participativa, de modo a contribuir para: a elevação da qualidade de vida de sua população, e proteção de seu patrimônio natural, histórico, étnico e cultural; a busca da qualidade ambiental da Zona Costeira, identificando suas potencialidades, vulnerabilidades e tendências predominantes, como elemento essencial para o processo de gestão; a incorporação da dimensão ambiental nas políticas setoriais voltadas à gestão integrada dos ambientes costeiros e marinhos; e também visa ao efetivo controle sobre os agentes causadores de poluição ou degradação ambiental sob todas as formas que ameacem a qualidade de vida na Zona Costeira e a produção e difusão do conhecimento necessário ao desenvolvimento e aprimo- ramento das ações de Gerenciamento Costeiro (MMA. 2004). Moraes (1999, p. 116) diz ainda que:

[..]O Plano Nacional de Gerenciamento Costeiro busca planejar e acompanhar o processo de ocupação da zona costeira, disciplinando os usos do solo com a definição de áreas de preservação, mas também com a indicação de áreas para uma exploração planejada (sustentável) dos recursos litorâneos [...], trata-se de um programa não apenas restritivo, mas também indutor.

Depois de 20 anos da Conferência de Estocolmo, o Rio de Janeiro reuniu, em 1992, líderes de 178 países na Conferência das Nações Unidas sobre Meio Ambiente e Desenvolvimento (CNUMAD) para discutir novamente a questão ambiental global, onde foi firmado um compromisso mundial para implementação de ações, visando alcançar um desenvolvimento em bases sustentáveis. Este compromisso, denominado Agenda 21, constitui-se num documento contendo recomendações sobre as questões que impedem ou dificultam a promoção do desenvolvimento sustentável nas sociedades atuais, quer sejam ricas ou pobres.

No capítulo 8 da Agenda 21 há toda uma abordagem da necessidade de integração de fatores econômicos, sociais e ambientais e da garantia de maior participação do público no processo de tomada de decisão em todos os níveis do poder. Mostra que é preciso formular internamente políticas que reflitam uma perspectiva em longo prazo, levando em conta os vínculos existentes entre as diversas questões políticas, econômicas, sociais e ambientais envolvidas no processo de desenvolvimento .

O capítulo 5 da Agenda 21, que trata da dinâmica demográfica e da sustentabilidade, explicita a necessidade dos Governos locais e gerenciamento municipais de atentar para o crescimento demográfico nas cidades. Esse capítulo ressalta que "os fatores humanos devem ser adequadamente levados em consideração na formulação de políticas abrangentes para o desenvolvimento sustentável" e que deve ser estudado o impacto de tendências demográficas sobre os meios tradicionais de subsistência de grupos indígenas e comunidades locais, inclusive nas alterações do crescimento demográfico sobre o uso tradicional da terra. O Capítulo 26 também trata da necessidade de reconhecimento e respeito às populações indígenas e comunidades tradicionais, bem como da importância da participação dessas populações no desenvolvimento loca $4^{4}$

O capítulo 17 da Agenda 21, chama atenção para a proteção dos oceanos e das zonas costeiras, demonstrando a necessidade de gerenciamento integrado e o

\footnotetext{
${ }^{4}$ Disponível em: < http://www.bdt.fat.org.br/publicacoes/politica/agenda21> Acesso em: 13/07/2011
} 
desenvolvimento com bases sustentáveis das regiões litorâneas. Nesse capítulo ressalta-se que as zonas costeiras contém z habitats diversificados e produtivos, relevantes para o desenvolvimento de núcleos urbanos, oferecendo condições para a manutenção de subsistência de muitas vilas tradicionais, mas também gerando a possibilidade de acúmulo de riquezas através da exploração desses recursos. Esses habitats devem ser considerados e analisados na sua complexidade de interRelações. nele o "meio ambiente marinho [...] e as zonas costeiras adjacentes" são, de início, avaliados como "uma riqueza que oferece possibilidades para um desenvolvimento sustentável" mostrando, então, a necessidade de seu "gerenciamento integrado". (MORAES 1999, p. 157).

O capítulo 17 dessa agenda aponta ainda, entre outras questões, que os estados costeiros devem comprometer-se com a prática da gestão integrada e sustentável das suas zonas costeiras e do meio ambiente marinho sob suas jurisdições nacionais. Nesse contexto, é urgente a definição de políticas públicas, focando a tomada de decisões, através da inclusão de todos os atores sociais envolvido\$ 5 e a devida identificação dos vários usos atuais dos territórios costeiros e as interações entre esses usos. Passa a ser também responsabilidade dos estados nacionais a promoção do desenvolvimento de modelos que contabilizem e/ou identifiquem essa diversidade ambiental sob sua jurisdição de forma a refletir também, quaisquer alterações de valor decorrentes de utilizações de zonas costeiras e marinhas, inclusive processos como poluição, erosão marinha, perda de recursos naturais e destruição de habitats. Ainda nesse capítulo é recomendada para a zona costeira, entre outras, as seguintes ações:

- A implementação de planos e programas integrados de gerenciamento e desenvolvimento sustentável das zonas costeiras;

- A preparação de perfis costeiros que identifiquem as áreas críticas, inclusive as regiões erodidas, os processos físicos, os padrões de desenvolvimento, os conflitos entre os usuários e as prioridades específicas em matéria de gerenciamento;

- A melhoria dos estabelecimentos humanos costeiros, especialmente no que diz respeito à habitação,

${ }^{5}$ Os setores envolvidos deveriam incluir todas as comunidades presentes na zona costeira, inclusive as populações indígenas (Cap 26 da Agenda 21), representantes governamentais e de Organizações Não governamentais (ONG), cientistas e demais membros da sociedade civil que se interessassem. água potável, tratamento e depósito de esgotos, resíduos sólidos e efluentes industriais e a integração dos programas setoriais relativos ao desenvolvimento sustentável de estabelecimentos humanos ligados a agricultura, turismo, pesca, portos e indústrias que utilizem ou se relacionem à área costeira.

No entanto, é importante enfatizar que a Agenda 21 "é uma proposta vinculada ao desenvolvimento vigente, fortalecendo o papel dos grupos principais que representam o "núcleo duro" do modelo sócio-econômico dominante, ou seja, a economia e o mercado, enquanto os setores sociais são chamados a participar apenas das questões relativas às áreas sociais e ambientais". (RATTNER, 2000). Alcançar os objetivos de sustentabilidade discutidos na Agenda 21, implicará na inclusão de todos os setores da sociedade no processo de planejamento, execução e atribuições de benefícios e responsabilidades.

No ano de 1996, a zona costeira brasileira foi incluída no planejamento estratégico do Governo Federal através do "Plano Plurianual" (PPA) e do programa "Brasil em Ação" que traziam, no seu interior, a ideia de sustentabilidade, mas cuja finalidade estava voltada para programas de saneamento e desenvolvimento urbano, visando o crescimento turístico e portuário. Os espaços costeiros são controlados pelo governo federal, sendo este o responsável pelos principais programas relacionados à gestão da zona costeira. Daí ser de sua responsabilidade a criação e a fiscalização de áreas de proteção, unidades de conservação, parques, reservas, estações ecológicas dentre outras, como também o estabelecimento dos bens de uso comum como as praias, rios, praças, ruas e salvaguarda de sua integridade.

A União é um dos principais agentes indutores da ocupação dessas áreas, com as instalações de equipamentos públicos de médio impacto como os campos universitários, quartéis militares, hospitais federais. (MORAES, 1999, p.160). Como também é um dos agentes mais impactantes identificados na zona costeira, tendo em vista a instalação autoritária de algumas instituições como a Petrobrás ou mesmo a construção de portos e complexos industriais na zona costeira que prejudicam o meio, quer seja pela magnitude de sua intervenção na paisagem e pelo número de suas instalações no litoral, quer seja pelas operações de alto risco ambiental e conflitos sociais gerados.

Programas como o "Brasil em Ação" e o "Avança Brasil", cujas premissas são a construção de grandes obras de infra-estrutura com grande visibilidade, havendo pouca preocupação com a qualidade de vida local 
ou regional. E ainda:

[..] A concepção dos programas, embora incorpore a linguagem do desenvolvimento sustentável, está ancorada nos conceitos desenvolvimentistas próprios da Revolução Industrial: a transformação do mundo físico, por meio de impactos de grande escala, e a busca de uma produtividade material avaliada por meio de um viés de escala economicista e imediatista. Grandes obras, grandes cidades, futuro megalomaníaco, produção como fator de progresso voltada ao mercado externo. (SANTOS 2003 p. 39)

Destaca-se ainda o Guia Metodológico de Gestão Integrada da Zona Costeira da UNESCO, que trata da importância da cooperação entre usuários, cientistas e responsáveis pelas decisões no reconhecimento dos problemas da zona costeira e na busca por soluções. Neste documento, o litoral é considerado um "eco-sócio-sistema", um espaço composto e complexo, onde ocorrem interações entre componentes físicos, biológicos e "antropogênicos", cuja qualificação do litoral deve ser realizada de acordo com esses componentes e as respectivas interações entre eles.(UNESCO, 1997).

Nesse guia da UNESCO é destacada a importância da Gestão Integrada da Zona Costeira (GIZC), pois esta se tornou uma necessidade dada a crescente pressão sobre os ambientes litorâneos. (UNESCO, 1997). Logo, a Gestão Integrada da Zona Costeira é uma atividade de gerenciamento que busca, fundamentalmente, a construção de um modelo cooperativo entre os diversos níveis e setores do governo, e destes com a sociedade. A Gestão Integrada é:

[...] Um processo dinâmico, contínuo e iterativo destinado a promover a gestão sustentável das zonas costeiras. [...] Procura equilibrar, a longo prazo, os benefícios do desenvolvimento econômico e das utilizações humanas da zona costeira; os benefícios que advêm da proteção, preservação e restauração das zonas costeiras; os benefícios da minimização da perda de vidas humanas e de bens; e os benefícios do acesso e usufruto públicos das zonas costeiras, sempre dentro dos limites estipulados pela dinâmica e capacidade de cargas naturais. (COMISSÃO EUROPEIA 1999 p. 15)

A definição de gestão integrada como gestão sustentável foi destacada pela Comissão Europeia:

[...]A gestão sustentável das áreas costeiras visa atingir o máximo bem possível, a longo prazo, para a sociedade, abarcando preocupações ambientais, econômicas, sociais e culturais. Pretende promover a justiça social através de uma distribuição mais justa das oportunidades, quer entre a população atual quer entre as gerações atuais e as futuras. (COMISSÃO EUROPEIA. 1999 p.15)

Sachs (1993 apud CARRARA, 2003, p. 25 - 27) falando sobre a sustentabilidade integrada diz que, para planejar o desenvolvimento para um país, região, estado ou município é necessário considerar, ao mesmo tempo, a sustentabilidade social, econômica, ecológica, espacial e cultural. A sustentabilidade social está fundamentada na ideia de uma sociedade voltada para o ser, e isso só seria possível com a construção de um outro tipo de desenvolvimento, mais voltado para o homem. A sustentabilidade a partir do viés econômico envolve mecanismos alternativos do sistema produtivo, que precisa de uma integração local, em que a eficiência econômica seja avaliada por "critérios macrossociais" e não apenas pela "lucratividade microempresarial". No que se refere à sustentabilidade ecológica esta considera a gestão integrada dos recursos naturais, objetivando o um maior aproveitamento de tais recursos, tendo por base a eliminação do desperdício e uma maior otimização dos recursos.

A sustentabilidade espacial está voltada para uma otimização territorial, tanto no que diz respeito às forças produtivas que geram riquezas, como no que diz respeito aos assentamentos humanos. "Consiste em ampliar o leque de opção econômica sem, no entanto, desajustar" a cultura de cada local. A sustentabilidade cultural envolve o ações que busquem não só a preservação dos ecossistemas, mas também o enraizamento da identidade e da diversidade cultural local, gerando um despertar para as tradições e os valores locais, visando o repasse às gerações futuras.

Dessa forma, evidencia-se um largo arcabouço teórico que gira em torno da sustentabilidade e as medidas que devem ser efetivadas para a que a discussão não fique apenas no plano da utopia. No entanto, as questões ligadas ao capital, e que passam pela discussão de valor de uso e valor de troca, e que tomam como cenário dessas relações, o litoral e suas diferentes formas de uso, refletem um distanciamento dos preceitos da sustentabilidade, até mesmo quando a atividade produtiva é o turismo.

\section{CONSIDERAÇÕES FINAIS}

Na zona costeira, a convivência entre a sustentabilidade e as diversas possibilidades de uso, resulta em conflitos, tornando essas áreas cada vez mais carentes de iniciativas que visem o bem-estar coletivo, que busquem o desenvolvimento de fato.

O litoral, apesar de ser detentor de uma variedade de opções no que diz respeito ao desenvolvimento econômico, dentre elas, a pesca, a agricultura, a indústria, a carcinicultura e o turismo, vem se limitando, na maioria das vezes, ao desenvolvimento desta última atividade de forma não planejada e não participativa, configurando 
assim, o distanciamento do tão almejado desenvolvimento sustentado. O turismo como atividade redentora da economia das áreas litorâneas, só tem grandes possibilidades de concretização, quando trabalhado na perspectiva do desenvolvimento local, comunitário, e em parceria e/ou concomitante com as atividades tradicionais, de forma a não anular atividades que já existam no lugar, como a pesca artesanal, pois os núcleos pesqueiros, normalmente, acabam se tornando atrativo turístico, e sendo assim, é preciso atentar para que a prática do turismo não se transforme em uma grande vilã das áreas litorâneas.

Afora essa questão de o turismo ser tratado como redentor econômico das localidades litorâneas, e essa prática ser desenvolvida, quase sempre, sem o devido planejamento, há ainda o fato da falta de engajamento entre as diversas esferas de atores sociais que atuam ou administram as zonas costeiras, o que culmina em um processo de deslitoralização, no sentido de que a população local vem perdendo sua identidade. Em geral, embora essas pessoas vivam no litoral, já não se sentem mais ou não são mais percebidas como povos do mar, já que as atividades econômicas tradicionais do litoral começam a ser substituídas por atividades ligadas ao turismo, gerando funções como barraqueiros, guias, bugueiros, dentre outras. Assim, a população local começa a passar por um processo de desterritorialização, tendo que territorializar outras áreas mais distantes do mar, ao mesmo tempo que nas proximidades do mar ocorre outra reterritorialização, cujos atores passam a ser pessoas e/ou empresas exógenas à comunidade local, atribuindo ao lugar, unicamente, valores de troca, descaracterizando, portanto, a paisagem litorânea.

Diante do exposto, é vital para a manutenção econômica das localidades litorâneas, a implantação de um processo de Gestão integrada da Zona Costeira, para que haja a convivência pacífica e até complementar de atividades como o turismo e a pesca; que aconteça o respeito ao meio ambiente original, incluindo aqui as tradições da população; o manejo adequado dos recursos naturais e o desenvolvimento econômico.

\section{REFERÊNCIAS}

BARBIERI, J. Organizações inovadoras: estudos e casos brasileiros. 1988.

CARRARA, a. Sustentabilidade local: uma análise comparativa. In: SANTOS, M.; SOUZA, M. A. A.; DESILVEIRA, M. L. (Ed.). Sustentabilidade local: uma análise comparativa. : Petrópolis, 2003.
CMMAD, C. M. sobre o Meio Ambiente e o D. p. 49, 1988.

COMISSÃO EUROPEIA. Ecodesenvolvimento: crescer sem destruir. : Luxemburgo: Serviço das Publicações Oficiais das Comunidades Europeias, 1999. ISBN 92-828-6467-7.

CORRÊA, R. L. Territorialidade e corporação: um exemplo. In: SANTOS, M.; SOUZA, M. A. A.; DESILVEIRA, M. L. (Ed.). Território: globalização e fragmentação. : Hucitec, 2002. p. 251-256.

DIEGUES, A. C. S. O mito moderno da natureza intocada. 4. ed. : Hucitec São Paulo, Braz, 2004.

GABRIELLI, C. P.; SANTOS, G. N. Turismo de base comunitária e patrimônio cultural imaterial no nordeste brasileiro. Caderno Virtual de Turismo, v. 16, n. 3, 2016.

IBAMA. Geo Brasil 2002: Perspectivas do Meio Ambiente no Brasil. : Edições IBAMA, 2002. ISBN $85-7300-144$ - 5.

IBGE. Atlas geográfico das zonas costeiras e oceânicas do Brasil. 2011. ISBN = 9788524042195 .

LOUREIRO, V. R. Os parceiros do mar: natureza e conflito social na pesca da amazônia. Belém: Conselho Nacional De Desenvolvimento Científico e Tecnológico, 1985.

MMA. Plano Nacional de Gerenciamento Costeiro (PNGC II). 2004. Disponível em: <http://www.mma. gov.br/estruturas/orla/_arquivos/pngc2.pdf.> Acesso em: $25 / 10 / 2004$.

MORAES, A. C. R. Contribuições para a gestão da zona costeira do Brasil: elementos para uma geografia do litoral brasileiro. : Annablume, 1999. v. 47. ISBN 978 - 857419 - 677 - 0.

QUEIROZ, J.; KITAMURA, P. Desenvolvimento de códigos da conduta para uma aqüicultura responsável. Panorama da Aquiicultura, 2001.

RATTNER, H. Brasil no limiar do século XXI: alternativas para a construção de uma sociedade sustentável. : Editora da Universidade de São Paulo, 2000. ISBN 85-314-0590-5.

SACHS, I. Ecodesenvolvimento: crescer sem destruir. : Vértice, 1993. ISBN-13: 9788585068219. 
SANTOS, A. D. d. e. a. Políticas ambientais no brasil: análises, instrumentos e experiências. In: LITTLE, P. E. (Ed.). O programa "Avança Brasil" e o Plano Plurianual 2000-2003: para onde vai o desenvolvimento sustentável? Oxford: IEB, 2003. cap. 10.

UNESCO. Methodological guide to integrated coastal zone management. : UNESCO, 1997.

A UNESCO e o Ano Internacional do Turismo Sustentável. 2017. Disponível em: <http://www.unesco.org/new/pt/brasilia/ about-this-office/prizes-and-celebrations/ 2017-international-year-of-sustainable-tourism/> Acesso em: 20/02/2017. 